\title{
PERFIL SOCIODEMOGRÁFICO E MOTIVOS DO ESPECTADOR DE BASQUETEBOL
}

\author{
MS. RUI DANIEL GASPAR NETO BISCAIA \\ Doutorando em Gestão do Desporto na Faculdade de Motricidade \\ Humana da Universidade Técnica de Lisboa (FMH-UTL, Lisboa - Portugal) \\ Docente visitante na FMH-UTL e no Instituto Piaget (Almada - Portugal) \\ e-mail: biscaia.rui@gmail.com
}

\author{
DR. ABEL HERMÍNIO LOURENÇO CORREIA \\ Doutor em Ciências do Desporto pela FMH-UTL (Lisboa - Portugal) \\ Professor Associado do Departamento de Ciências do Desporto da FMH-UTL \\ (Lisboa - Portugal) \\ e-mail: acorreia@fmh.utl.pt \\ DR. ANTÓNIO FERNANDO BOLETO ROSADO \\ Doutor em Ciências do Desporto pela FMH-UTL (Lisboa - Portugal) \\ Professor Associado com Agregação do Departamento de Ciências do \\ Desporto da FMH-UTL (Lisboa - Portugal) \\ e-mail: arosado@fmh.utl.pt
}

\begin{abstract}
RESUMO
O objectivo deste estudo foi identificar as motivações dos espectadores de basquetebol e o seu perfil sociodemográfico. Recolheram-se 459 questionários em oito jogos dos play-offs 2008 da Liga de Clubes de Basquetebol em Portugal e através duma análise factorial identificou-se que o sentimento de pertença à equipa e cidade, escape, família, conhecimento do jogo, apreciar as habilidades técnicas dos jogadores, interesse nos jogadores e drama são os motivos mais importantes. Na análise sociodemográfica verificou-se uma grande variabilidade entre espectadores de acordo com a idade, género, habilitações literárias, agregado familiar, rendimentos, proximidade geográfica, número de acompanhantes e prática de basquetebol.
\end{abstract}

PALAVRAS-CHAVE: Espectadores; basquetebol; perfil sociodemográfico. 
A análise do comportamento dos espectadores nos eventos desportivos, dada a sua relevância nas sociedades actuais, tem assumido um crescente protagonismo na investigação académica. Em Inglaterra, por exemplo, os jogos da principal liga de futebol foram assistidos por mais de 13 milhões de espectadores em 2007/2008' e nos EUA, durante o mesmo período, as assistências da principal liga de basquetebol ascenderam os 23 milhões de espectadores². Conhecer os factores que influenciam as pessoas a assistir aos jogos é crucial para as organizações do desporto, pois vai permitir atrair mais espectadores e aumentar a notoriedade dos clubes e modalidades desportivas. Neste contexto, diversos autores têm desenvolvido escalas para tentar explicar os motivos das pessoas para assistir aos jogos desportivos (TRAIL; JAMES et al., 200 I ; FUNK, 200I; JAMES; ROSS, 2004; WON; KITAMURA, 2007). Estas escalas têm sido aplicadas em diferentes modalidades e tipos de espectadores, verificando-se a importância de algumas variáveis para explicar as assistências aos jogos.

Zhang et al. (2003) apuraram que as características sociodemográficas têm uma forte relação com o consumo e ajudam a compreender o comportamento dos espectadores, verificando-se poder discriminante na localidade (LOUGH; KIM, 2004; FERREIRA; BRAVO, 2007), idade e factores económicos (PAN et al., 1997; DESBORDES; OHL; TRIBOU, 1999), etnia (PONS et al., 200 I; ARMSTRONG; PERETTO STRATTA, 2004) ou género (RIDINGUER; JAMES, 2002; HALL; O'MAHONY, 2006). Outra variável importante é a escolha da modalidade desportiva. No basquetebol verifica-se que os atributos mais valorizados entre os espectadores são a popularidade (FERREIRA; ARMSTONG, 2004), conhecimento do jogo (KHALE et al., 200 I; RIDINGUER; JAMES, 2002), identificação com a equipa (LOUGH; KIM, 2004; BROKAW; STONE; JONES, 2006) e entretenimento antes e durante os jogos (PEASE; ZHANG, 200 I; LOUGH; KIM, 2004).

Estas investigações apresentam alguns indicadores importantes para a gestão de espectadores, no entanto, a informação está dispersa e continua a ser insuficiente para determinar as razões que levam as pessoas a deslocar-se aos espectáculos de basquetebol. Urge por isso reunir informação sobre as motivações das pessoas para assistir aos jogos, de forma a garantir a notoriedade da modalidade e potenciar o interesse dos patrocinadores. Posto isto, o principal objectivo deste estudo é identificar os motivos dos espectadores de basquetebol, testando a aplicabilidade duma escala (WON; KITAMURA, 2007) que, apesar de ter sido validada nos jogos de futebol da Coreia do Sul e do Japão, reúne os principais motivos apontados na literatura

I. Premier League Handbook 2007/08 (mww.premierleague.com). Consultado em: 23 de Jan. 2009.

2. NBA Attendance Report 2009 (www.nba.com). Consultado em 23 de Jan. 2009. 
supracitada sobre basquetebol. Procedemos, naturalmente, à validação da escala estudando as suas qualidades psicométricas de validade, fiabilidade e sensibilidade. Complementarmente, determina-se o perfil sociodemográfico dos espectadores.

\section{METODOLOGIA}

\section{AMOSTRA}

A amostra foi constituída pelos espectadores dos jogos da LCB ${ }^{3}$. Aplicaram-se 577 questionários durante oito jogos da primeira fase dos play-offs 2008. Todos os questionários foram preenchidos pelos espectadores e, após eliminados os que estavam incompletos, obteve-se uma amostra final de 459 questionários. A recolha foi efectuada no primeiro encontro realizado em casa por cada equipa, de modo a obter informação sobre os espectadores de todos os clubes que participaram na prova. Todos os inquiridos foram informados previamente da natureza do estudo, participaram de forma voluntária e garantiu-se o anonimato e a confidencialidade das suas respostas (PORTUGAL, 1998). As datas dos jogos, equipas participantes, localidade e número de questionários válidos recolhidos podem ser observadas na tabela I.

Tabela I. Questionários: data, jogo, cidade, distrito, percentagem da população.

\begin{tabular}{|c|c|c|c|c|c|}
\hline Data & Jogo & Localidade & $\begin{array}{l}\text { Bilhetes } \\
\text { vendidos }\end{array}$ & $\begin{array}{l}\text { Questionários } \\
\text { válidos }\end{array}$ & $\begin{array}{l}\text { População } \\
\text { (\%) }\end{array}$ \\
\hline 12 abr.08 & $\begin{array}{l}\text { Ovarense } x \\
\text { Barreirense }\end{array}$ & Ovar (Aveiro) & 342 & 77 & 22,5 \\
\hline 12 abr.08 & $\begin{array}{l}\text { Ginásio Figuei- } \\
\text { rense x C .A. B. }\end{array}$ & $\begin{array}{l}\text { Figueira da Foz } \\
\text { (Coimbra) }\end{array}$ & 201 & 63 & 31,3 \\
\hline 13 abr.08 & $\begin{array}{l}\text { F. C.Porto X } \\
\text { Belenenses }\end{array}$ & Matosinhos (Porto) & 472 & 135 & 28,6 \\
\hline 13 abr.08 & Vagos $\times$ Lusitânia & $\begin{array}{l}\text { Oliveira do Bairro } \\
\text { (Aveiro) }\end{array}$ & 107 & 31 & 29,0 \\
\hline 17 abr.08 & $\begin{array}{l}\text { Barreirense } x \\
\text { Ovarense }\end{array}$ & Barreiro (Setúbal) & 198 & 52 & 26,3 \\
\hline 17 abr.08 & $\begin{array}{l}\text { C.A.B. } \times \text { Ginásio } \\
\text { Figueirense }\end{array}$ & Funchal (Madeira) & 113 & 24 & 21,2 \\
\hline 18 abr.08 & $\begin{array}{l}\text { Belenenses x } \\
\text { F. C.Porto }\end{array}$ & Lisboa (Lisboa) & 206 & 63 & 30,6 \\
\hline I 8 abr.08 & Lusitânia x Vagos & $\begin{array}{l}\text { Angra Heroísmo } \\
\text { (Açores) }\end{array}$ & 67 & 14 & 20,9 \\
\hline Total $=$ & & & 1645 & 459 & 27,9 \\
\hline
\end{tabular}

3. LCB (Liga de Clubes de Basquetebol) - organização de direito privado que organizou até ao final da época 07/08 o campeonato profissional em Portugal. 
Foi utilizado um questionário para identificar os motivos e o perfil sociodemográfico dos espectadores. A escala de Won e Kitamura (2007), dado o aperfeiçoamento relativo a modelos anteriores e identificação dos motivos mais apontados nos estudos sobre espectadores de basquetebol (KHALE et al., 200 I ; RIDINGUER; JAMES, 2002; FERREIRA; ARMSTRONG, 2004; LOUGHT; KIM, 2004), foi utilizada para medir o comportamento de assistir aos jogos. Os I I motivos (identificação com a equipa, interesse nos jogadores, orgulho na comunidade, entretenimento, drama, escape, habilidades técnicas, interacção social, família, realização pessoal e conhecimento do jogo) foram apresentados nos 32 itens propostos pelos autores, numa escala numérica 1 - 10 ( 1 =discordo totalmente; 10 =concordo totalmente). A tradução dos itens para a língua portuguesa foi efectuada por um licenciado em ciências do desporto e educação física com vasta experiência no basquetebol e revista por três investigadores seniores da área da gestão do desporto. Por sua vez, o perfil sociodemográfico foi definido através de sete indicadores (idade, género, habilitações literárias, número de pessoas do agregado familiar, rendimentos familiares, proximidade geográfica e o número de acompanhantes), aos quais se acrescentou uma questão sobre a prática de basquetebol federado (joga ou jogou basquetebol como federado?). Antes da aplicação do questionário foi conduzido um pré-teste a 25 espectadores escolhidos aleatoriamente no jogo da fase regular da LCB entre Belenenses e Lusitânia, resultando daqui a inclusão da variável proximidade geográfica da residência ao pavilhão.

\section{PROCEDIMENTOS}

Foram constituídas equipas de três entrevistadores para todos os recintos dos clubes que participaram nos play-offs 2008. Os elementos receberam formação inicial para a recolha dos dados ${ }^{4}$. No dia dos jogos afixaram-se cartazes na

4. O recrutamento dos entrevistadores foi efectuado entre os alunos da licenciatura em Gestão do Desporto da Faculdade de Motricidade Humana da Universidade Técnica de Lisboa. Na semana anterior à recolha dos dados efectuou-se uma reunião com os entrevistadores para se explicar os objectivos do estudo, a estratégia de abordagem aos espectadores e a localização dos entrevistadores nos recintos. No final entregaram-se os questionários, canetas, cartazes, folhetos e normas de recolha dos dados, e realizou-se um teste de aplicação dos questionários entre os participantes.

Normas de recolha de dados: (a) localização dos cartazes nos recintos; (b) localização dos entrevistadores; (c) âmbito e objectivos do estudo; (d) abordagem aos espectadores - "boa tarde, somos da (...) a estamos a realizar um estudo sobre (...). Temos um questionário para entregar a todos os espectadores. As respostas são anónimas e utilizadas apenas para investigação. Podemos contar com o seu contributo? Obrigado." 
entrada principal dos recintos desportivos e nas bilheteiras. Todos os cartazes indicaram os objectivos do estudo e sua importância para os clubes e a modalidade. Seguidamente, referiu-se a protecção dos dados pessoais (PORTUGAL, 1998) e pediu-se a participação dos espectadores. No acto da compra do bilhete entregou-se um panfleto aos espectadores com a mesma informação dos cartazes e na porta de entrada dos recintos ficaram dois entrevistadores com questionários e canetas. $\bigcirc$ preenchimento foi feito pelos próprios espectadores, antes do início do jogo, assim que se sentavam na bancada, sendo a recolha efectuada logo nesse momento pelo terceiro entrevistador. No intervalo foram recolhidos os restantes questionários pelos três elementos da equipa de entrevistadores.

\section{TRATAMENTO DOS DADOS}

tratamento dos dados foi efectuado através do Statistical Package for the Social Sciences (SPSS), versão 16.0 for Windows. Utilizaram-se as frequências absolutas e relativas para definir o perfil sociodemográfico dos espectadores e as médias e desvios padrão para os motivos. $\bigcirc$ estudo das qualidades psicométricas do questionário envolveu uma análise factorial exploratória (varimax rotation) de componentes principais com extracção de factores pelo critério de Kaiser (eigenvalues > I). Retiraram-se os itens cujas saturações eram inferiores a 0,50 (PESTANA; GAGEIRO, 2003), bem como os factores com apenas um ou dois itens (HAKSTIAN; ROGERS; CATTELL, 1982). A consistência interna dos factores foi confirmada através do teste alpha de Cronbach. Para medir a sensibilidade da escala utilizaram-se os coeficientes de curtose e simetria.

\section{RESULTADOS E DISCUSSÃO}

\section{PERFIL SOCIODEMOGRÁFICO DOS ESPECTADORES}

A análise sociodemográfica indica uma grande heterogeneidade entre os espectadores de basquetebol, sugerindo que a modalidade é apelativa para um leque muito alargado de pessoas, independentemente das suas condições sociais e demográficas, conforme se pode observar na Tabela 2. 
Tabela 2. Valores da estatística descritiva para o perfil sociodemográfico.

\begin{tabular}{|c|c|c|c|}
\hline & Frequência & $\%$ & $\%$ acumulada \\
\hline \multicolumn{4}{|l|}{ Idade $(n=459)$} \\
\hline-20 & 27 & 5,9 & 5,9 \\
\hline $20-29$ & $|0|$ & 22,0 & 27,9 \\
\hline $30-39$ & 128 & 27,9 & 55,8 \\
\hline $40-49$ & 117 & 25,5 & 81,3 \\
\hline $50-59$ & 53 & 11,5 & 92,8 \\
\hline+60 & 33 & 7,2 & 100 \\
\hline \multicolumn{4}{|l|}{ Género $(n=457)$} \\
\hline Masculino & 293 & 64,1 & 64,1 \\
\hline Feminino & 164 & 35,9 & 100 \\
\hline \multicolumn{4}{|c|}{ Habilitações literárias $(n=455)$} \\
\hline Ensino Básico & 39 & 8,6 & 8,6 \\
\hline Ensino Secundário & 214 & 47,0 & 55,6 \\
\hline Curso médio/ Bacharelato & 64 & 14,1 & 69,7 \\
\hline $\begin{array}{l}\text { Licenciatura } \\
\text { Pós-grad/MSc/PhD }\end{array}$ & $\begin{array}{l}116 \\
22\end{array}$ & $\begin{array}{l}25,5 \\
4,8\end{array}$ & $\begin{array}{l}95,2 \\
100\end{array}$ \\
\hline \multicolumn{4}{|l|}{ Agregado familiar $(n=447)$} \\
\hline 1 & 46 & 10,3 & 10,3 \\
\hline 2 & 80 & 17,9 & 28,2 \\
\hline 3 & 153 & 34,2 & 62,4 \\
\hline 4 & 134 & 30,0 & 92,4 \\
\hline$\geq 5$ & 34 & 7,6 & \\
\hline \multicolumn{4}{|c|}{ Rendimento do agregado familiar $(n=404)$} \\
\hline$-599 €$ & 30 & 7,4 & 7,4 \\
\hline $600 €-999 €$ & 48 & 11,9 & 19,3 \\
\hline $1000 €-1499 €$ & 92 & 22,7 & 42,0 \\
\hline I500€- I899€ & 53 & 13,1 & 55,1 \\
\hline $1900 €-2499 €$ & 62 & 15,3 & 70,4 \\
\hline $2500 €-3499 €$ & 54 & 13,3 & 83,7 \\
\hline $3500 €-4100 €$ & 29 & 7,2 & 90,9 \\
\hline$+4100 €$ & 37 & 9,1 & 100 \\
\hline \multicolumn{4}{|c|}{ Proximidade geográfica $(n=446)$} \\
\hline$-\mathrm{l} \mathrm{km}$ & 62 & 13,9 & 13,9 \\
\hline $\mathrm{lkm}-5 \mathrm{~km}$ & 159 & 35,7 & 49,6 \\
\hline $5 \mathrm{~km}-10 \mathrm{~km}$ & 118 & 26,5 & 76,0 \\
\hline$+10 \mathrm{~km}$ & 107 & 24,0 & 100 \\
\hline \multicolumn{4}{|c|}{ Número de acompanhantes $(n=433)$} \\
\hline 0 & 28 & 6,5 & 6,5 \\
\hline I & 63 & 14,5 & 21,0 \\
\hline 2 & 139 & 32,1 & 53,1 \\
\hline 3 & 113 & 26,1 & 79,2 \\
\hline 4 & 47 & 10,9 & 90,1 \\
\hline$\geq 5$ & 41 & 10,0 & 100 \\
\hline \multicolumn{4}{|c|}{ Prática de basquetebol $(n=457)$} \\
\hline Sim & 306 & 67,0 & 67,0 \\
\hline Não & $|5|$ & 33,0 & 100 \\
\hline
\end{tabular}


Os resultados indicam uma grande diversidade na idade dos espectadores, aspecto também verificado noutras investigações sobre basquetebol (DICK; TURNER, 2007; LOUGH; KIM, 2004; ZHANG et al., 2003). Destaca-se ainda assim a elevada representatividade dos jovens (27,9\% tem menos de 30 anos) e das pessoas na fase típica de maior actividade familiar e profissional (53,4\% tem idades compreendidas entre 30 e 49 anos), diminuindo o interesse com o envelhecimento (DESBORDES; OHL; TRIBOU, 1999).

Estas evidências sugerem que os jogos reúnem um conjunto de características que são apelativas para as pessoas durante as fases mais activas das suas vidas, mantendo-se o interesse durante bastante tempo, pelo que é importante promover a modalidade desde as idades mais jovens.

\section{GÉNERO}

universo da amostra é maioritariamente masculino (64,1\%), indicando que os homens continuam a responder mais ao apelo do desporto. Esta situação é visível também noutras modalidades tradicionais, como o futebol (CORREIA; ESTEVES, 2007) ou o golfe (IRWIN et al., 2003), mas também nos desportos radicais, como o freestyle motocross (KO; PARK; CLAUSSEN, 2008). No entanto, a elevada taxa de participação das mulheres (35,9\%) vem confirmar a tendência para o esbatimento das diferenças entre géneros na assistência a eventos desportivos (CUNNINGHAM; KWON, 2003), realçando a importância deste segmento para as organizações de desporto.

\section{HABILITAÇÕES LITERÁRIAS}

A maioria dos espectadores (47\%) terminou o ensino secundário e quase metade $(44,6 \%)$ prosseguiu a vida académica em instituições de ensino superior, tendo $1 / 4$ dessas pessoas terminado a licenciatura e 4,8\% avançado com formações especializadas. Estes resultados indicam níveis de escolaridade bem acima dos distritos onde decorreram os jogos pesquisados (Lisboa com maior percentagem de licenciados - 13,5\%) e da média portuguesa ( 13,9\% com ensino secundário e 8,6\% com ensino superior). Além disso, assemelham-se com outras pesquisas no basquetebol norte-americano (DICK; TURNER, 2007). É de referir que as elevadas habilitações

5. XIV Recenseamento Geral da População Portuguesa (www.dolceta.eu/). Consultado em 26 de Jun. 2008. 
têm uma relação positiva com a compra de ingressos anuais para assistir a todos os jogos (bilhetes de época). Ross (2007) identificou que 80,6\% dos compradores destes bilhetes apresentam formação académica superior, aspecto indicativo duma valorização do basquetebol entre as pessoas mais instruídas.

\section{AGREGADO FAMILIAR}

Zhang (2003) identificaram que os espectadores de basquetebol feminino nos EUA vivem predominantemente em agregados familiares compostos por um máximo de 4 pessoas (88,7\%), facto que é confirmado neste estudo. Apenas 7,6\% dos espectadores vivem em famílias com 5 ou mais elementos, tendência que atesta a realidade dos agregados portugueses, onde somente $9,5 \%$ das famílias ultrapassam as quatro pessoas. Ainda assim, nos EUA, os constituintes de agregados com somente duas pessoas representam a maior fatia de espectadores (37,7\%), contrariamente à tendência de 3 elementos por família que se verifica naquele país ${ }^{6}$. Já em Portugal, são os espectadores oriundos de famílias com 3 a 4 pessoas que estão mais representados nas bancadas dos recintos de jogo (64,2\%), apesar das famílias com dois elementos serem as mais representativas do território português $(29,8 \%)$.

\section{RENDIMENTOS}

A análise dos rendimentos confirma o pouco poder discriminante desta variável entre os espectadores desportivos (ZHANG et al., 2003; IRWIN, 2003; DICK; TURNER, 2007). Ainda assim, convém referir a sua importância na compra dos bilhetes de época, sobretudo entre os espectadores que vivem em agregados familiares com maiores rendimentos económicos (PAN et al., I 997; ROSS, 2007). De realçar que o preço dos bilhetes na primeira fase dos play-offs 2008 teve um valor fixo de sete euros, estipulado pela LCB.

\section{PROXIMIDADE GEOGRÁFICA}

Pan et al ( 1997) apuraram que a maioria dos espectadores demora 30-60 minutos da sua residência ao local de jogo, estando os que vivem nas proximidades mais representados apenas nos jogos a meio da semana. No nosso estudo optámos por analisar a distância, dada a maior objectividade na criação de estratégias promocionais. Concluímos que os espectadores com residência mais próxima não são os mais representados nas bancadas. A faixa mais representativa reside a $1 \mathrm{~km}-5 \mathrm{~km}$, verificando-se

6. Census profile 2000 - U. S. Summary (www.census.gov) Consultado em: 26 de Jun. 2008. 
que a partir deste intervalo, o aumento da distância do local da residência tem um impacto negativo no comportamento de assistir aos jogos. Para tal, pode contribuir não só o tempo necessário nas deslocações como o facto dos jogos terem duração aproximada de duas horas, implicando que as pessoas que vivem em locais afastados destinem uma grande parte do dia para esse efeito, esforço que parece não compensar quando o objectivo é assistir a um jogo de basquetebol.

\section{NÚMERO DE ACOMPANHANTES}

A maioria dos espectadores do nosso estudo (93\%) assiste aos jogos acompanhados e, de acordo com Lough e Kim (2004), os familiares e amigos são a companhia preferencial entre os espectadores de basquetebol. Este facto sugere que os recintos de jogo são espaços privilegiados de interacção familiar e socialização entre os membros da comunidade. Neste estudo não foi recolhida informação sobre a tipologia dos acompanhantes. No entanto, dada a sua pertinência para as estratégias de gestão dos espectadores, recomenda-se a identificação dos acompanhantes em futuras investigações.

\section{PRÁTICA DE BASQUETEBOL}

○ conhecimento da ligação dos espectadores à modalidade enquanto praticantes é um dado importante para perceber se o basquetebol tem um raio de acção limitado aos jogadores, ex-jogadores e outros intervenientes directos, ou se, pelo contrário, consegue captar a atenção de outras pessoas. Os resultados indicam que a massa de espectadores ultrapassa as barreiras do basquetebol, uma vez que $2 / 3 \mathrm{da}$ amostra não pratica nem nunca praticou esta modalidade. No entanto, a elevada percentagem de pessoas presentes nos pavilhões que são ou foram jogadores sugere que a modalidade tem um papel relevante nas suas vidas, mesmo após deixarem a prática. Assim, dada a receptividade do jogo, consideramos fundamental realçar as características da modalidade na promoção dos jogos, bem como desenvolver estratégias que visem aumentar o número de praticantes, facto que vai ter reflexos positivos a curto prazo e com repercussões também a médio e longo prazo, dada a ligação que os jogadores mantêm com o basquetebol.

\section{MOTIVOS}

VALIDAÇÃO PSICOMÉTRICA DA ESCALA

A validação da escala entre os espectadores portugueses foi efectuada através duma análise factorial com rotação varimax, utilizando-se o alpha de Cronbach para 
aferir a consistência interna dos factores obtidos. Mediu-se ainda a sensibilidade da escala com base nos coeficientes de curtose e achatamento dos factores, indicando os mesmos (valores próximos de 0) a existência duma distribuição normal com boa capacidade de discriminar os sujeitos. $\bigcirc$ processo de validação permitiu identificar que, contrariamente aos onze motivos antecipados, o comportamento de assistir aos jogos de basquetebol é explicado por apenas sete factores, com níveis de consistência internos satisfatórios (alpha global=0,87), permitindo estes explicar quase $2 / 3$ da variância dos resultados $(60,91 \%)$.

Tabela 3. Resultados da Análise Factorial Exploratória (varimax rotation).

\begin{tabular}{|c|c|c|c|c|}
\hline Factores / itens* & Loading & Eigenvalue & $\%$ acumulada & $\alpha$ \\
\hline $\begin{array}{l}\mathrm{FI} \text { - Sentimento de pertença à equipa e } \\
\text { cidade }\end{array}$ & & 7,21 & 22,52 & 0,86 \\
\hline $\begin{array}{l}\text { Considero-me um verdadeiro adepto da } \\
\text { minha equipa }\end{array}$ & 0,61 & & & \\
\hline $\begin{array}{l}\text { Sinto-me orgulhoso quando a equipa da minha } \\
\text { cidade ganha }\end{array}$ & 0,61 & & & \\
\hline $\begin{array}{l}\text { Sinto-me realizado quando a minha equipa } \\
\text { ganha }\end{array}$ & 0,73 & & & \\
\hline $\begin{array}{l}\text { Ser adepto da minha equipa é muito impor- } \\
\text { tante para mim }\end{array}$ & 0,69 & & & \\
\hline $\begin{array}{l}\text { Vou aos jogos para apoiar a equipa da minha } \\
\text { cidade }\end{array}$ & 0,56 & & & \\
\hline $\begin{array}{l}\text { Sinto-me orgulhoso quando a minha equipa } \\
\text { joga bem }\end{array}$ & 0,82 & & & \\
\hline $\begin{array}{l}\text { Sinto as vitórias da minha equipa como se } \\
\text { fossem minhas }\end{array}$ & 0,77 & & & \\
\hline F2 - Escape & & 3,37 & 33,05 & 0,77 \\
\hline $\begin{array}{l}\text { Assistir aos jogos permite-me sair da realidade } \\
\text { do dia-a-dia }\end{array}$ & 0,78 & & & \\
\hline Os jogos são um escape à minha rotina diária & 0,79 & & & \\
\hline $\begin{array}{l}\text { Gosto de ir aos jogos porque esqueço os } \\
\text { meus problemas }\end{array}$ & 0,75 & & & \\
\hline F3 - Família & & 2,25 & 40,07 & 0,92 \\
\hline $\begin{array}{l}\text { Os jogos de basquetebol permitem-me passar } \\
\text { tempo com a minha família }\end{array}$ & 0,90 & & & \\
\hline $\begin{array}{l}\text { Estar com a família é a razão pela qual gosto } \\
\text { de ir aos jogos de }\end{array}$ & 0,89 & & & \\
\hline $\begin{array}{l}\text { Ir aos jogos de basquetebol permite-me criar } \\
\text { união com a minha família }\end{array}$ & 0,88 & & & \\
\hline F4 - Conhecimento do jogo & & 2,13 & 46,73 & 0,84 \\
\hline
\end{tabular}




\begin{tabular}{|c|c|c|c|c|}
\hline Factores / itens* & Loading & Eigenvalue & $\%$ acumulada & $\alpha$ \\
\hline $\begin{array}{l}\text { Acompanho regularmente as estatísticas de } \\
\text { jogadores }\end{array}$ & 0,79 & & & \\
\hline $\begin{array}{l}\text { Conheço habitualmente os resultados das } \\
\text { equipas }\end{array}$ & 0,77 & & & \\
\hline $\begin{array}{l}\text { Leio regularmente os resultados e estatísticas } \\
\text { da equipa }\end{array}$ & 0,86 & & & \\
\hline $\begin{array}{l}\text { F5 - Apreciar as habilidades técnicas dos } \\
\text { jogadores }\end{array}$ & & 1,68 & 51,99 & 0,60 \\
\hline $\begin{array}{l}\text { Gosto de ir aos jogos para ver as habilidades } \\
\text { dos jogadores }\end{array}$ & 0,51 & & & \\
\hline $\begin{array}{l}\text { Os jogos de basquetebol permitem-me socia- } \\
\text { lizar com outras pessoas }\end{array}$ & 0,55 & & & \\
\hline $\begin{array}{l}\text { Gosto de ver bons desempenhos técnicos } \\
\text { dos jogadores }\end{array}$ & 0,71 & & & \\
\hline $\begin{array}{l}\text { Aprecio as capacidades atléticas dos joga- } \\
\text { dores }\end{array}$ & 0,66 & & & \\
\hline F6 - Interesse nos jogadores & & 1,50 & 56,66 & 0,78 \\
\hline $\begin{array}{l}\text { Assisto aos jogos mais por causa de certos } \\
\text { jogadores do que pela equipa }\end{array}$ & 0,78 & & & \\
\hline $\begin{array}{l}\text { A principal razão para assistir aos jogos é poder } \\
\text { ver o meu jogador }\end{array}$ & 0,82 & & & \\
\hline $\begin{array}{l}\text { Sou mais admirador dalguns jogadores que } \\
\text { propriamente da equipa }\end{array}$ & 0,81 & & & \\
\hline F7 - Drama & & 1,36 & 60,91 & 0,74 \\
\hline $\begin{array}{l}\text { Gosto mais do jogo quando é renhido/dispu- } \\
\text { tado até ao fim }\end{array}$ & 0,84 & & & \\
\hline $\begin{array}{l}\text { Prefiro ver jogos renhidos/disputados do que } \\
\text { jogos fáceis para }\end{array}$ & 0,84 & & & \\
\hline $\begin{array}{l}\text { Gosto de ver jogos em que o resultado é } \\
\text { incerto }\end{array}$ & 0,74 & & & \\
\hline
\end{tabular}

A estrutura factorial (tabela 3) reteve 26 itens que se agruparam em 7 factores, contrariamente à escala original de 32 itens divididos por I I factores (WON; KITAMURA, 2007). Dos 6 itens eliminados por fraca saturação (loading<0,5), dois pertenciam originalmente ao domínio do entretenimento (gosto de ir aos jogos de basquetebol porque é divertido; os jogos de basquetebol são uma boa maneira de passar o meu tempo) e dois à interacção social (gosto dos jogos de basquetebol porque me dão a oportunidade de estar com os meus amigos; gosto de interagir com os outros espectadores quando vou aos jogos). Foi ainda eliminado um terceiro item do entretenimento (a razão principal para gostar de basquetebol é por achar o desporto um bom entretenimento) e um 
outro do orgulho na comunidade (é por estar ligado à cidade que acabo por gostar da equipa) que, apesar que terem boa saturação (loading $\geq 0,5$ ) e estarem correlacionados, não mostraram níveis aceitáveis de consistência interna $(\alpha<0,60)$. Os itens com boa saturação originários da identificação com a equipa (considero-me um verdadeiro adepto da minha equipa; ser adepto da minha equipa é muito importante para mim), ao orgulho na comunidade (sinto-me orgulhoso quando a equipa da minha cidade ganha; vou aos jogos para apoiar a equipa da minha cidade) e à realização pessoal (sinto-me realizado quando a minha equipa ganha; sinto-me orgulhoso quando a minha equipa joga bem; sinto as vitórias da minha equipa como se fossem minhas) agruparam-se em torno de um factor comum, ao qual se denominou sentimento de pertença à equipa e cidade. $\bigcirc$ item da interacção social com boa saturação (os jogos de basquetebol permitem-me socializar com outras pessoas) agrupou-se com os três itens originários das habilidades técnicas, constituindo-se o factor apreciar as habilidades técnicas dos jogadores. Os restantes itens com bons níveis de saturação mantiveram o agrupamento da escala original, pelo que se retiveram os factores escape, família, conhecimento do jogo, interesse nos jogadores e drama. Relativamente à consistência interna, todos os factores identificados apresentaram níveis satisfatórios $(0,60 \leq \alpha \leq 0,92)$. $\bigcirc$ factor que melhor explica a variância nos resultados é o sentimento de pertença à equipa e cidade (22,52\%), enquanto que no extremo oposto de situa o drama (4,25\%).

\section{MOTIVOS DOS ESPECTADORES PORTUGUESES}

As respostas obtidas aos itens utilizados para medir os motivos dos espectadores de basquetebol são apresentadas na Tabela 3. Os resultados variam entre 3,13 (assisto aos jogos mais por causa de certos jogadores do que pela equipa) e 9, 17 (gosto mais do jogo quando é renhido/disputado até ao fim), observando-se pouca identificação dos espectadores com a ideia de assistir aos jogos por causa de certos jogadores. 
Tabela 4. Médias (M) e desvio padrão (dp) dos itens que representam os motivos dos espectadores portugueses.

\begin{tabular}{|c|c|c|}
\hline Motivos / itens & M & Dp \\
\hline \multicolumn{3}{|l|}{ Sentimento de pertença à equipa e cidade } \\
\hline Considero-me um verdadeiro adepto da minha equipa & 8,54 & 2,09 \\
\hline Sinto-me orgulhoso quando a equipa da minha cidade ganha & 9,13 & 1,80 \\
\hline Sinto-me realizado quando a minha equipa ganha & 7,59 & 2,56 \\
\hline Ser adepto da minha equipa é muito importante para mim & 7,25 & 2,62 \\
\hline Vou aos jogos para apoiar a equipa da minha cidade & 7,69 & 2,80 \\
\hline Sinto-me orgulhoso quando a minha equipa joga bem & 8,59 & 1,95 \\
\hline Sinto as vitórias da minha equipa como se fossem minhas & 7,25 & 2,68 \\
\hline \multicolumn{3}{|l|}{ Escape } \\
\hline Assistir aos jogos permite-me sair da realidade do dia-a-dia & 6,41 & 2,77 \\
\hline Os jogos são um escape à minha rotina diária & 6,29 & 2,78 \\
\hline Gosto de ir aos jogos porque esqueço os meus problemas & 4,66 & 2,82 \\
\hline \multicolumn{3}{|l|}{ Família } \\
\hline Os jogos de basquetebol permitem-me passar tempo com a minha família & 5,02 & 3,20 \\
\hline Estar com a família é a razão pela qual gosto de ir aos jogos de basquetebol & 4,49 & 3,07 \\
\hline Ir aos jogos de basquetebol permite-me criar união com a minha família & 4,55 & 3,06 \\
\hline \multicolumn{3}{|l|}{ Conhecimento do jogo } \\
\hline Acompanho regularmente as estatísticas de jogadores & 5,90 & 2,89 \\
\hline Conheço habitualmente os resultados das equipas & 8,06 & 2,26 \\
\hline Leio regularmente os resultados e estatísticas da equipa & 7,03 & 2,77 \\
\hline \multicolumn{3}{|l|}{ Apreciar as habilidades técnicas dos jogadores } \\
\hline Gosto de ir aos jogos para ver as habilidades dos jogadores & 6,92 & 2,28 \\
\hline Os jogos de basquetebol permitem-me socializar com outras pessoas & 7,22 & 2,16 \\
\hline Gosto de ver bons desempenhos técnicos dos jogadores & 8,81 & 1,47 \\
\hline Aprecio as capacidades atléticas dos jogadores & 7,47 & 2,24 \\
\hline \multicolumn{3}{|l|}{ Interesse nos jogadores } \\
\hline Assisto aos jogos mais por causa de certos jogadores do que pela equipa & 3,13 & 2,71 \\
\hline A principal razão para assistir aos jogos é poder ver o meu jogador favorito & 3,70 & 2,81 \\
\hline Sou mais admirador de alguns jogadores do que propriamente da equipa & 3,78 & 2,74 \\
\hline \multicolumn{3}{|l|}{ Drama } \\
\hline Gosto mais do jogo quando é renhido/disputado até ao fim & 9,17 & 1,47 \\
\hline \multirow{2}{*}{$\begin{array}{l}\text { Prefiro ver jogos renhidos/disputados do que jogos fáceis para uma das } \\
\text { equipas }\end{array}$} & 8,93 & 1,80 \\
\hline & 8,22 & 2,16 \\
\hline Gosto de ver jogos em que o resultado é incerto & & \\
\hline
\end{tabular}


O sentimento de pertença à equipa e cidade é um factor muito valorizado e que realça a importância do reconhecimento social (TRAIL; JAMES, 200 I) e da identificação da equipa com a cidade. Estes aspectos remetem para o desejo de pertença ao "grupo basquetebol" e consequente imagem da modalidade (WANN et al., 200 I ) entre os espectadores. Nas habilidades técnicas verificaram-se também diferenças, dado que os espectadores motivados pela estética do jogo associam este prazer à possibilidade de interagir com outras pessoas que partilham o gosto pela performance atlética dos jogadores (WANN, 1995). Estes resultados sugerem diferenças entre os espectadores de basquetebol em Portugal, mais influenciados pela identidade social, em contraposição aos espectadores de futebol na Coreia do Sul e Japão, focados essencialmente nos seus motivos pessoais.

Quanto aos restantes factores, notou-se a existência dum conjunto de motivos comuns aos espectadores desportivos, nomeadamente o escape ao desgaste das rotinas diárias e a possibilidade de passar tempo em família (WANN, 1995; TRAIL; JAMES, 200 I; MATSUOKA; HUJIMOTO, 2003; JAMES; ROSS, 2004), bem como alguns aspectos que distinguem o desporto doutras formas de entretenimento, tais como o drama e o interesse em jogadores específicos (FUNK et al., 200 I ; BROKAW; STONE; JONES 2006) ou o conhecimento do jogo (RIDINGUER; JAMES, 2002; FERREIRA; ARMSTRONG, 2004).

\section{CONCLUSÕES}

Através do nosso estudo concluímos que o basquetebol reúne um público com características sociodemográficas diversificadas. Observa-se uma grande heterogeneidade na idade, começando o interesse nos jogos a manifestar-se entre os mais jovens e diminuindo substancialmente a partir dos 50 anos. As assistências são compostas sobretudo por homens, os níveis de escolaridade são altos e os agregados familiares compostos maioritariamente por três a quatro pessoas, apresentando rendimentos bastante variados. Os espectadores que vivem a I km-5km são os mais representados nas bancadas, verificando-se ainda que os indivíduos se deslocam aos recintos de jogo acompanhadas por duas a três pessoas e que a maioria não joga nem nunca jogou basquetebol federado.

No que respeita aos motivos, o comportamento de assistir aos jogos é explicado por sete factores. Confirmou-se a existência dum conjunto de motivos frequentemente identificados na literatura para as várias modalidades desportivas, nomeadamente o escape, a família, o conhecimento do jogo, o interesse nos jogadores e o drama, emergindo no entanto deste estudo dois outros motivos que são o sentimento de pertença à equipa e cidade e apreciar as habilidades técnicas dos jogadores, aspectos que colocam ênfase na imagem social do basquetebol. 
Através das evidências deste estudo podemos fazer algumas recomendações de marketing. Assim, é essencial comunicar os jogos de forma diferenciada, consoante as características pessoais e motivos identificados entre os espectadores, de forma a posicionar o basquetebol face às ofertas concorrentes. Este aspecto favorece também a captação de apoios, uma vez que conhecendo os mercados alvo, o basquetebol torna-se mais apelativo para os potenciais patrocinadores.

Por fim, importa referir que as diferenças identificadas face ao modelo inicial induzem a necessidade de confirmar estes motivos em futuras pesquisas sobre basquetebol em outros países. A escala de sete factores identificada apresentou qualidades psicométricas que garantem a sua aplicabilidade para identificar os motivos dos espectadores de basquetebol da amostra. No entanto, sugere-se que novas pesquisas, com recurso à escala de Won e Kitamura (2007), sejam efectuadas para aferir se estes motivos são específicos dos espectadores portugueses ou se podem ser generalizados a uma massa crítica mais abrangente dos espectadores de basquetebol. Além disso, o produto deste estudo, apesar de fornecer algumas pistas para o desenvolvimento de estratégias de gestão, não permite avaliar o resultado da experiência de assistir a um jogo, pelo que se torna essencial analisar o impacto dos motivos na satisfação e lealdade, de forma a encetar verdadeiras políticas de gestão de espectadores.

\section{Sociodemographic Profile and Motives of Basketball Spectators}

ABSTRACT: This study aimed to identify people's motives to attend basketball games and their socio-demographics characteristics. A total of 459 questionnaires were answered within eight play-offmatches at the Liga de Clubes de Basquetebol 2008 championship and through a factor analysis it was possible to identify that belonging to city and team, escape, family, knowledge of the game, physical skills, interest in player and drama are the most important motives. The demographics analysis suggests diversity in spectators according to age, gender, education level, household, income, geographical proximity, companion and basketball experience. KEYWORDS: Spectators; basketball; sociodemographic profile.

\section{Perfil sociodemográfico y Motivos de los espectadores del Baloncesto}

RESUMEN: El objeto de este estudio fue identificar las motivaciones de los espectadores de baloncesto y su perfil sociodemográfico. Se recogieron 459 cuestionarios en ocho partidos de los play-offs 2008 de la Liga de Clubs de Baloncesto en Portugal y a través de una análisis factorial se concluye que las motivaciones más importantes para acudir a las canchas son el sentimiento de pertenencia al equipo y a la ciudad, el escape, la familia, el conocimiento del juego, el disfrute de las habilidades técnicas de jugadores, el interés por los jugadores y el drama. En el análisis sociodemográfico, se comprueba una gran variabilidad entre el público en función de la edad, género, educación, la unidad familiar, las rentas, proximidad geográfica, número de acompañantes y práctica del baloncesto.

PALABRAS CLAVE: Espectadores; baloncesto; perfil sociodemográfico. 


\section{REFERÊNCIAS}

ARMSTRONG, K.; PERETTO STRATTA, T. Market analyses of race and sport consumption. Sport Marketing Quarterly. West Virginia, v. 13, n. I, p. 7-16, 2004.

BROKAW, A.; STONE, G.; JONES, M. Model of the factors contributing to fan support at small-college athletic events. The Sport Journal. Daphne, v. 9, n. 4, 2006. Disponível em: $<$ www.thesportjournal.org/article/model-factors-contributing-fan-support-small-collegeathletics-events>. Acesso em: 19 dez. 2007.

CORREIA, A.; ESTEVES, S. An exploratory study of spectator's motivation in football. International Journal of Sport Management and Marketing. United Kingdom, v. 2, n. 5/6, p. 572-590, 2007.

CUNNINGHAM, G.; KWON, H. The theory of planned behaviour and intentions to attend a sport event. Sport Management Review. Australia, v. 6, n. 2, p. 127-145, 2003.

DESBORDES, M. ; OHL, F. ; TRIBOU, G. Marketing du sport. Paris : Económica Publisher, 1999.

DICK, R.; TURNER, B. Are fans and NBA marketing directors on the same page? A comparison of value of marketing techniques. Sport Marketing Quarterly. West Virginia, v. I6, n. 3, p.|40-|46, 2007.

FERREIRA, M.; ARMSTRONG, K. An exploratory examination on attributes influencing student's decisions to attend college sport events. Sport Marketing Quarterly. West Virginia, v. 13, n. 4, p. 194-208, 2004.

FERREIRA, M.; BRAVO, G. A multilevel model analysis of professional soccer attendance in Chile 1990-2002. International Journal of Sports Marketing and Sponsorship, Bristol, v. 8, n. 3, p. 254-27।, 2007.

FUNK, D. et al. Development of the sport interest inventory (SII): implications for measuring unique consumer motives at team sporting events. International Journal of Sports Marketing and Sponsorship. Bristol, v. 3, p. 291-316, 2001.

HALL, J.; O'MAHONY, B. An empirical analysis of gender differences in sports attendance motives. International Journal of Sports Marketing and Sponsorship. Bristol, v. 7, n 4, p. 334 345, 2006.

HAKSTIAN, A. R.; ROGERS, W. T.; CATTELL, R. B. The behaviour of number-of-factors rules with simulated data. Journal of Marketing. Chicago, v. 62, p. 30-45, 1982.

IRWIN, R. et al. Cause-related sport sponsorship: an assessment of spectator beliefs, attitudes, and behavioral intentions. Sport Marketing Quarterly. West Virginia, v. 12, n. 3, p. 13 1-139, 2003.

JAMES, J.; ROSS, S. Comparing sport consumer motivations across multiple sports. Sport Marketing Quarterly, West Virginia. v. 13, n. I, p. 17-25, 2004. 
KHALE, L. et al. The social values of fans for men's versus women's university basketball. Sport Marketing Quarterly. West Virginia, v. 10, v. 2, p. I56-162, 2001.

KO, Y. J.; PARK, H.; CLAUSSEN, C. L. Action sports participation: consumer motivation. International Journal of Sports Marketing and Sponsorship. Bristol, v. 9, n. 2, p. I I I - I 24, 2008.

LOUGH, N.; KIM, A. Analysis of sociomotivations affecting spectator attendance at women's basketball games in South Korea. Sport Marketing Quarterly. West Virginia, v. I3, n. I, p. 35-42, 2004.

MATSUOKA, H.; HUJIMOTO, J. A comparative analyses of motivation of spectating professional soccer and baseball. In: Japanese Society of Sport Industry. Proceedings of the $12^{\text {th }}$ Annual Conference of Japanese Society of Sport Industry. Tokio, Japan, p. 66-67, 2003.

PAN, D. W. et al. Factors and differential effects on purchases of season tickets for intercollegiate basketball games. Journal of Sport Behavior, South Alabama, v. 20, v. 4, p. I25-142, 1997.

PEASE, D. G.; ZHANG, J. Socio-motivational factors affecting spectator attendance at professional basketball games. International Journal of Sport Management, Boston, v. 2, p. $3|-59,200|$.

PESTANA, M. H.; GAGEIRO, J. N. Análise de dados para ciências sociais - A complementaridade do SPSS. 3. ed. Lisboa: Edições Sílabo, 2003.

PONS, F. et al. Role of sporting events as ethnoculture's emblems: impact of acculturation and ethnic identity on consumers orientation toward sporting events. Sport Marketing Quarterly, West Virginia, v. 10, v. 4, p. 231-240, 2001.

PORTUGAL. Lei n. ${ }^{\circ}$ 67/98, de 26 de Outubro. Regula a protecção de dados pessoais (transpõe para a ordem jurídica portuguesa a directiva 95/46/CE, do Parlamento Europeu e do Conselho, de 24 de Outubro de 1995, relativa à protecção das pessoas singulares no que diz respeito ao tratamento dos dados pessoais e à livre circulação desses dados). Disponível em: < http://www.cnpd.pt/bin/legis/nacional/lei_6798.htm>. Acesso em: 20 mar. 2008.

RIDINGUER, L.; JAMES, J. Female and male sport fans: a comparison of sport consumption motives. Journal of Sport Behavior. South Alabama, v. 25, n. 3, p. 260-278, 2002.

ROSS, S. Segmenting fans using brand associations: a cluster analysis. Sport Marketing Quarterly. West Virginia, v. 16, n. I, p. 15-24, 2007.

TRAIL, G.; JAMES, J. The motivation scale of sport consumption: assessement of the scale's psychometric properties. Journal of Sport Behavior, South Alabama, v. 24, p. 108- 127, 2001.

WANN, D. Preliminary validation of the sport fan motivation scale. Journal of the Sport and Social Issues. Boston, v. 20, p. 377-396, 1995.

WANN, D. et al. Sport fans. The psychology and social impact of spectators. Great Britain: Routledge, 2001 . 
WON, J.; KITAMURA, K. Comparative analysis of sport consumer motivations between South Korea and Japan. Sport Marketing Quarterly. West Virginia, v. I6, n. 2, p. 93-I 05, 2007.

ZHANG, J. et al. Understanding women's professional basketball game spectators: sociodemographics, game consumption, and entertainment options. Sport Marketing Quarterly. West Virginia, v. 12, n. 4, p. 228-243, 2003.

Recebido: 02 fev. 2009

Aprovado: 20 set. 2010

Endereço para correspondência:

Rui Daniel Gaspar Neto Biscaia Av. D. João II, n. ${ }^{\circ} \mid$ I 0, R/C C 1990- 366, Lisboa (Parque das Nações)

Portugal 